\title{
Effects of radioiodine administration on serum concentrations of matrix metalloproteinases, adiponectin and thrombospondin
}

\author{
Andrzej Lewiński ${ }^{1}$ Anna Brona², Diana Jędrzejuk², Anna Bohdanowicz-Pawlak², Krzysztof C Lewandowski", \\ Małgorzata Bieńkiewicz ${ }^{3}$, Andrzej Milewicz ${ }^{2}$
}

From 4th Congress of the Polish Thyroid Association 2013

Lodz, Poland. 11-13 April 2013

\section{Introduction}

In order to assess long-term safety of radioactive iodine administration in treatment of thyrotoxicosis, we assessed concentrations of selected markers of risk cardiovascular disease, i.e. matrix metalloproteinase 2 (MMP-2), its main inhibitor TIMP-2, matrix metalloproteinase 9 (MMP-9), its main inhibitor TIMP-1, as well concentrations of anti-inflammatory adiponectin and pro-inflammatory thrombospondin.

\section{Material and methods}

The study involved 23 patients ( 3 males) age $53 \pm 12$ (mean \pm SD) years treated with radioiodine for thyrotoxicosis. Serum concentrations TSH, fT4, fT3, MMP-2, MMP-9, TIMP-1, TIMP-2, adiponectin and thrombospondin were measured just before radioiodine administration (visit 1 ), and subsequently, after 7 days (visit 2), 3 months (visit 3), six to eight months (visit 4) and 15-18 months after radioiodine administration (visit 5).

\section{Results}

There were no acute changes in serum concentrations of MMP-2, MMP-9, TIMP-1 and TIMP-2 adiponectin and thrombospondin (visit 1 versus visit 2). Subsequently, however, there was no change in serum MMP9 or thrombospondin, but an increase in MMP-2 (from $393 \pm 106 \mathrm{ng} / \mathrm{ml}$, to $774 \pm 424 \mathrm{ng} / \mathrm{ml}$ ), TIMP-1 (from $177 \pm 76 \mathrm{ng} / \mathrm{ml}$ to $296 \pm 118 \mathrm{ng} / \mathrm{ml}$ ), TIMP-2 (from 136 $\pm 44 \mathrm{ng} / \mathrm{ml}$ to $168 \pm 41 \mathrm{ng} / \mathrm{ml}$ ), and adiponectin (from $16442 \pm 9490 \mathrm{ng} / \mathrm{ml}$ to $23518 \pm 9840 \mathrm{ng} / \mathrm{ml}$ ), visit 1 to visit 5 respectively, $\mathrm{p}<0.01$ ). Further analysis, however, revealed no significant change in MMP-2/TIMP-2 ratio, but there was a significant decrease in MMP-9/TIMP-1 ratio $(\mathrm{p}<0.05)$, suggestive of possible decrease in concentrations of free MMP-9.

\section{Conclusions}

Our data reveal a significant and sustained increase in serum adiponectin as well as possible decrease of concentration of free MMP-9 after radioiodine administration. This might indicate overall safety of radioiodine treatment of thyrotoxicosis in terms of the risks of cardiovascular disease.

\section{Acknowledgements}

The study was financed from the grant of the Polish Ministry of Science and Higher Education, number NN402 476637 (Medical University of Lodz internal grant number: 507-11-384).

\section{Author details}

'Department of Endocrinology and Metabolic Diseases, Medical University of Lodz, Poland. ${ }^{2}$ Department of Endocrinology, Diabetology and Isotope Therapy, Medical University of Wroclaw, Poland. ${ }^{3}$ Department of Quality Control and Radiation Protection, Medical University of Lodz, Poland.

Published: 5 April 2013

doi:10.1186/1756-6614-6-S2-A40

Cite this article as: Lewiński et al.: Effects of radioiodine administration on serum concentrations of matrix metalloproteinases, adiponectin and thrombospondin. Thyroid Research 2013 6(Suppl 2):A40. 